\title{
EUTOMIA
}

Revista de Literatura e Linguística

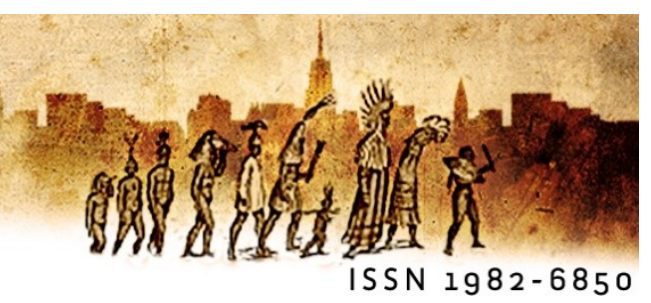

\section{Os brancos ouvem a fala da terra? A escuta na pesquisa acadêmica indígena}

\author{
Do Whites hear the speech of the earth? \\ Listening in indigenous academic research
}

Amilton Pelegrino de Mattos' (UFAC/UFRJ)

\begin{abstract}
Resumo: Este artigo parte da noção de "fala da terra", desenvolvida em pesquisa por acadêmicos da Licenciatura indígena da Universidade Federal do Acre, para refletir sobre a noção de escutar a terra. A ideia de escutar a terra ou "escuta poética" (PRIGOGINE e STENGERS, 1991) aparecerá em áreas diversas do pensamento ocidental da segunda metade do século $X X$, em obras que já problematizam a crise ecológica provocada pela modernidade e pensam como a ciência modela a relação do humano com o planeta e demais seres. Nesse processo, interessa-nos o papel daquilo que pode ser entendido como linguagem, articulado ao papel dos povos extramodernos, nessa tarefa de repensar a universidade e suas práticas na atualidade.
\end{abstract}

Palavras-chave: Pesquisadores indígenas; fala da terra; escuta; mito.

\begin{abstract}
This article starts with the notion of "speaking of the earth", developed in research by indigenous academics of the Federal University of Acre, to reflect on the notion of listening to the earth. The idea of listening to the earth or "poetic listening" (PRIGOGINE \& STENGERS, 1991) will appear in different areas of Western thought in the second half of the $20^{\text {th }}$ century, in works that already problematize the ecological crisis provoked by modernity and think how science models the relationship of the human with the planet and other beings. In this process, we are interested in the role of what can be understood as language, articulated with the role of extra-modern peoples, in this task of rethinking the university and its practices today.
\end{abstract}

Keywords: Indigenous researchers; speaking of the earth; listening; myth.

\section{Introdução}

Nós acadêmicos do curso de Licenciatura Indígena, grupo de seis etnias Hunikui, Nukini, Apurinã, Nawas, Apolina Arara e Katukina de várias regiões 
do estado do Acre tivemos a oportunidade, através desse trabalho, de trazer muitos conhecimentos para a comunidade acadêmica nesta instituição e iremos apresentar os trabalhos realizados nas nossas aldeias. Temos o objetivo de mostrar uma experiência sobre a fala da terra. Esse trabalho foi realizado com muito amor e dedicação, tudo voltado para nossos costumes e cultura da nossa aldeia e do nosso povo através de histórias, mitos e cantorias, danças, alimentação, bebidas e ilustrações. Tenham um bom aprendizado e boa leitura. (LICENCIATURA INDÍGENA, 2017)

O experimento de que vou tratar consiste numa pesquisa que envolveu três disciplinas e dois laboratórios ao longo do ano de 2017 e início de 2018 e foi desenvolvida por duas turmas da Licenciatura indígena da Universidade Federal do Acre (UFAC), Campus Floresta, junto às suas comunidades.

Além das atividades de sala e das pesquisas nos territórios desses povos, o projeto $A$ fala da terra resultou na realização de uma série de vídeos ${ }^{1}$, em dois livros que se basearam nas pesquisas feitas junto às comunidades, além de uma exposição de fotografias (LICENCIATURA INDÍGENA, 2017) em que os pesquisadores apresentaram o projeto à comunidade acadêmica.

A UFAC - Floresta é o campus da universidade situado no extremo ocidental do estado do Acre e do Brasil. Uma "universidade na floresta" com um projeto que busca refletir sobre essa condição. O que faz uma "universidade na floresta"? Qual a sua relação com o projeto moderno que caracteriza uma universidade em suas concepções e conceitos, práticas e escritas? Perguntas que atravessam as questões aqui colocadas.

Sou professor e pesquisador na área de Linguagens e Artes dessa Licenciatura indígena (LI) desde 2008. Meu trabalho no curso enfoca a prática de escrita em dois momentos. A escrita como prática pedagógica, que será manejada pelo professor na escola indígena diferenciada, tanto quanto a escrita como prática acadêmica de produção de uma pesquisa nesse contexto chamado igualmente diferenciado.

Trata-se então de um curso diferenciado. E o que o distingue dos demais cursos que não o seriam? Um curso diferenciado suporia que uma outra "cultura" está em jogo no

\footnotetext{
${ }^{1}$ Disponivel em: www.youtube.com/watch?v=DzOYXohFN 5 U\&t=715 www.youtube.com/watch? $v=$ Ejho7x $-9 f \mid \& t=1775$ www.youtube.com/watch? $v=$ DzOYXohFN 5 U\& $t=715$ www.youtube.com/watch?v=NsVmgjeJoQQ\& $t=125 w w w . y o u t u b e . c o m / w a t c h ? v=Q_{34} n 8 G e A O f A$ www.youtube.com/watch?v=cz3KR2aAWjo\&t=129s Acesso em: outubro de 2019.
} 
processo de formação. Portanto, de princípio, não se supõe que o aluno se encontre na mesma "cultura" que o professor ou a instituição acadêmica.

Por muito tempo, falar de cultura equivalia a falar de representação. As culturas seriam representações de uma realidade objetiva, que se supõe unificada na noção de natureza pela "ciência" (LATOUR, 1994, 2012). No início da década de 1960, no entanto, em sua obra O pensamento selvagem ([1962] 1997), o antropólogo Claude Lévi-Strauss propõe pensar essa relação entre cultura e natureza de uma outra perspectiva, imaginando um olhar selvagem que se volta sobre o civilizado e seu mundo. Frente ao problema de linguagem que seu projeto supõe, na medida em que esse outro pensamento prescinde do divisor natureza/cultura tal qual o conhecemos, o autor se debruça por mais de quatro décadas sobre os mitos dos povos ameríndios, compondo um experimento em que o seu pensamento se deixa transformar e variar pelo pensamento mítico.

Com esse projeto, Lévi-Strauss redefine o modo de se imaginar a "cultura", ao propor algo mais do que compreendê-la do ponto de vista dos ameríndios. O mitólogo se assemelharia a um traduttore, traditore (tradutor, traidor) de mundos, que se propõe a "trair", não o idioma alheio, mas sua própria "ontologia" (linguagem-natureza-cultura) ao traduzir esses outros mundos e suas alteridades (LÉVI-STRAUSS, 1975; VIVEIROS DE CASTRO, 2015, p. 243). Essa "traição" implica assim numa obra que já não supõe fidelidade a uma natureza unificada. Ao invés, a multiplicidade de mundos e a linguagem capaz de expressa-la é que passam ao primeiro plano.

Com esse projeto, o antropólogo também propõe, parafraseando a incontornável síntese de Roy Wagner, que todo esforço de compreensão de uma outra cultura é uma experimentação com a sua própria (2010, p. 12). Assim justifico a necessidade de tratar aqui da experiência acadêmica indígena também como um olhar que se volta sobre o saber dos modernos, na medida em que essa experiência impacta o projeto de universidade na floresta e nos desafia a pensar.

Desse modo, trabalhar em um contexto diferenciado é trabalhar em um contexto de abertura, de experimentação, de construção de acordos pragmáticos, de suspensão de certezas, de estranhamento de modelos. Mesmo a adoção do termo diferenciado deve supor sua contínua reconstrução, informada pela experiência de trabalho com os grupos interessados. 
Esse processo de formação em pesquisa pode ser pensado, portanto, estrategicamente (longe de um rótulo ou um modelo) como diferenciado e diferenciante no sentido de experimental, que se baseia em problemas, práticas e escritas concebidas coletivamente pelos acadêmicos junto a seus grupos. Portanto, não se trata de diferenciado como conceito fixo, ideia definida e fechada, mas como campo de experimentação, como linha de fuga ao modo ocidental de pensar por modelos (VIVEIROS DE CASTRO, 2018), como modelos de política pública, por exemplo.

A LI tem seu currículo organizado em dois momentos, cada qual com suas práticas. Um primeiro momento se dá na universidade, onde os grupos passam parte do semestre cursando disciplinas, e o outro nas comunidades quando os acadêmicos desenvolvem pesquisas junto ao seu povo.

Desse modo, trata-se de pensar o diferenciado como abertura à diferenciação, à experimentação a partir do que acontece especificamente, do que emerge no encontro de cada comunidade com seu pesquisador, nos modos como esse encontro e suas possibilidades são apropriados nessa interação, como a pesquisa e a universidade são apropriadas e transformadas em forma de percursos, práticas e escritas.

Opera-se na LI com a noção de áreas de conhecimento, as quais se desdobram em habilitações a partir da metade do percurso (UFAC, 2015). A área de Linguagens e Artes abrange um determinado campo de conhecimentos que inclui segundo a tradição ocidental o campo da linguagem verbal, bem como das demais linguagens que convencionamos como artísticas, tais como as artes visuais ou a música, que no caso acabam por incluir temas como grafismos, pinturas corporais, rituais.

Essa área se contrapõe às demais, que são Ciências e Humanidades. Em contraste com o divisor moderno que distingue as ciências da natureza e as ciências humanas, encontram-se as linguagens e a estética. Em suma, o sujeito (humanidades), o objeto (ciências) e o código (linguagens).

Quando se trata de um curso diferenciado, parece evidente que esse triedro já define de alguma maneira as regras do jogo. Visando problematizar (mais do que abolir) essa matriz, foi que em 2017 propus aos acadêmicos da LI, em uma disciplina de início de curso, Tópicos em pesquisa, um projeto voltado a debater e lidar com os pressupostos da noção de linguagem com que tanto a universidade quanto a escola operam. 
Esse projeto propunha a seguinte questão: A terra fala?

Em lugar de supor uma noção comum de linguagem, o objetivo inicial era buscar definir ou problematizar e contrastar o que poderia ser língua ou linguagem nos termos de povos para os quais a distinção entre sociedade e natureza não é a mesma que aquela que define o conhecimento científico dos modernos. Assim e com consequências inesperadas, tomava-se imediatamente distância dos termos em que está pressuposta a noção de língua/linguagem na concepção e na abordagem modernas do conhecimento.

Minha impressão, depois de alguns anos trabalhando com orientações de monografias de conclusão de curso (KAXINAWA, 2013; PINHANTA, 2013; PUYANAWA, 2013; SIÃ, 2013) e seus desdobramentos em projetos de pesquisa ${ }^{2}$ (MATTOS e IBÃ, 2017; MATTOS, 2018b), era que as noções de língua e linguagem pressupostas na universidade não levavam em consideração a noção de linguagem veiculada nas práticas de conhecimento indígenas. São essas práticas que vão referendar os temas das pesquisas desses acadêmicos, tanto quanto as práticas e as escritas que tais pesquisas exigem.

Trata-se de pesquisas de cantos, rituais, artes manuais e visuais, que por vezes não se referem diretamente aos mitos. Nessas pesquisas, porém, há um modo de conceber e manejar a linguagem e produzir escrita que parece próprio ao modo de operação do mito. Em suma, se o pensamento moderno concebe a linguagem e opera a escrita a partir da distinção entre natureza e cultura (representação), essa pesquisa indígena e sua escrita, que podemos entender como própria a um pensamento mítico, opera desde uma não distinção ou de uma combinação complexa dessas ordens (natureza e cultura).

A partir dessa experiência com a pesquisa indígena proponho me voltar aqui para as implicações de se tratar a questão da fala da terra na universidade. Meu objetivo é abordar assim certos pensadores que se propuseram a refletir sobre o modelo de pensamento moderno, suas características, práticas e escolhas, bem como os seus limites ecológicos. Isso inclui, certamente, a antropologia, disciplina que primeiro se voltou para o pensamento extramoderno, apontando sua importância para a compreensão do próprio projeto moderno e de sua ideia autoevidente do humano.

\footnotetext{
${ }^{2}$ Ver também Nixpu pima - Rito de passagem Huni Kuin. (Direção: Panteani Huni Kuin, 2015) Disponível em: https://www.youtube.com/watch?v=5jnnO1kEuDg Acesso em: outubro de 2019.
} 
Proponho ainda pôr em questão a ideia de escuta ou de ouvir, que juntamente com a noção de linguagem será colocada em variação (ou equivocação (VIVEIROS DE CASTRO, 2004)), sendo atravessada por outros sentidos. Isso porque ao atribuir outros significados a termos como língua, fala e mesmo visão ou texto, desloca-se a ideia do que é ouvir.

\section{Escutar a terra}

A terra fala? Trata-se de uma pergunta que também ecoa longe na tradição do conhecimento ocidental. Essa tradição tem no século XVII com a noção de representação (FOUCAULT, 1981; LATOUR, 1994) um momento fundamental marcado pela ideia de um saber cuja autoridade está fundada em um modo de questionar a natureza imaginado como neutro, transparente, que descreveria a realidade tal como se apresenta e, portanto, tal como ela é. A ciência se apresentaria assim como uma arguição da natureza politicamente desinteressada. Esse modo de conhecer reproduziria ainda o espírito de superioridade europeu em relação aos povos extramodernos.

Quais as implicações, portanto, de se fazer essa pergunta na universidade hoje e de faze-la da perspectiva dos povos ameríndios e outros extramodernos? Quais as noções de fala e de escrita que estão sendo mobilizadas quando se trata dessa linguagem que não é a linguagem transparente da representação? Visando avançar nessas questões, volto-me sobre algumas reconsiderações do projeto moderno elaboradas desde diferentes áreas.

Como afirma Antonio Candido, sabe-se que Guimarães Rosa compunha suas obras a partir de procedimento etnográfico, portanto, de uma escuta dedicada e atenta, uma escuta específica dos povos do sertão e suas histórias:

Eu ouvi falar de Guimarães Rosa pela primeira vez deve ter sido ali por 1944 ou, mais provavelmente, 1945. Eu estava na livraria Jaraguá e me encontrei com Vinicius de Moraes e Vinicius me disse que havia um colega dele do Itamaraty, que estava escrevendo uns contos, mas era um tipo muito peculiar, porque ele escrevia os contos preparando como se fosse um trabalho científico. Eram contos regionais e esse colega tinha fichário em que ele tinha todos os passarinhos, todos os acidentes geográficos, plantas com os nomes científicos, costumes como se estivesse fazendo um trabalho de sociologia. Aquilo eu achei muito interessante. (ANTONIO CANDIDO ${ }^{3}$ )

\footnotetext{
${ }^{3}$ Disponivel em: https://www.youtube.com/watch?v=VekkcAyxVdA Acesso em outubro de 2019.
} 
Em 1946 é lançado Sagarana de Guimarães Rosa, e desde essa primeira obra, livro "cheio de terra", Candido ([1946] 2002), já desloca o autor do rol dos regionalistas, que mantinham certa relação de "sujeito e objeto" entre o humano e o mundo que, segundo ele, se desfaz em Sagarana:

Por isso, sustento, e sustentarei, mesmo que provem o meu erro, que Sagarana não é um livro regional como os outros porque não existe região igual à sua, criada livremente pelo autor com elementos caçados analiticamente e, depois, sintetizados na ecologia belíssima das suas histórias. (CANDIDO, 2002, p. 185)

O sr. Guimarães Rosa construiu um regionalismo muito mais autêntico e duradouro, porque criou uma experiência total em que o pitoresco e o exótico são animados pela graça de um movimento interior, em que se desfazem as relações de sujeito e objeto para ficar a obra de arte como integração total de experiência. (Ib., p. 186)

De fato não se tratava mais da mesma relação com a terra. Com sua obra, Rosa propõe uma outra imagem da relação humano-terra-linguagem. Por mais importante que seja o papel do ambiente, já não se trata mais de paisagem ou natureza. O que interessa é como a linguagem redefine a relação entre humano e terra, como a indiscernibilidade entre humano e terra se dá pela linguagem (não sem conviver com aquela linguagem que também funda a separação entre humano e mundo).

O que Candido identifica desde a primeira escrita de Rosa é um outro modo de conceber essa relação, a que o escritor tem acesso ao adotar a pesquisa etnográfica como prática de criação literária. Mas que outro modo de relação com a terra é esse? De que modo Rosa faz dele um experimento de escrita?

No conto O recado do morro publicado em Corpo de baile em 1956, Guimarães Rosa narra o percurso de uma mensagem enunciada por um morro, o Morro da Garça. Essa mensagem acompanha os personagens ao longo do conto, até finalmente chegar a seu destinatário ocasional, aquele que está apto a ouvi-la, fazendo da mensagem um acontecimento.

À medida que um grupo de personagens percorre um trecho do sertão, paralelamente uma mensagem vai correndo, passando por personagens aptos a serem seus portadores e um assassinato vai se urdindo. Essas três tramas se entrelaçam tendo como eixo o enxadeiro Pedro Orósio, Pê-Boi, que guia um grupo composto por três pessoas importantes e um companheiro de serviço, que planeja o assassínio do principal. 
Episódio central se dá no encontro da comitiva com um "velhote grimo, esquisito, que morava dentro de uma lapa, entre barrancos e grotas": - "É o Gorgulho...". Surdo, é esse personagem que porta a mensagem que dá nome ao conto:

— "H'hum... Que é que o morro não tem preceito de estar gritando... Avisando de coisas..." - disse, por fim, se persignando e rebenzendo, e apontando com o dedo no rumo magnético de vinte e nove graus nordeste. (ROSA, 1978, p. 15)

Frei Sinfrão, um dos patrões que seguia no grupo, traduz em código oficial, exorcizando com explicação convincente e científica a alucinação de que supunha padecer o pagão:

— "Possível ter havido alguma coisa?" — frei Sinfrão perguntava. — "Essas serras gemem, roncam, às vezes, com retumbo de longe trovão, o chão treme, se sacode. Serão descarregamentos subterrâneos, o desabar profundo de camadas calcáreas, como nos terremotos de Bom-Sucesso (...). Dizem que isso acontece mais é por volta da lua-cheia..." (Ib., p. 15)

Gorgulho impressiona seu Alquiste, naturalista alemão que também compõe a comitiva, e ele o convida a acompanha-los. A certa altura da viagem, o velho ganha confiança e decide contar o que ouviu:

Mas, enquanto isso, seo Alquiste punha uma atenção aguda, quase angustiada, nas palavras do Gorgulho - frei Sinfrão e seo Jujuca se admiravam: como tinha ele podido saber que agora justamente o Gorgulho estava recontando a doidice aquela, de ter escutado o Morro gritar? Pois falava:

- Que que disse? Del-rei, ô, demo! Má-hora, esse Morro, ásparo, só se é de satanaz, ho! Pois-olhe-que, vir gritar recado assim, que ninguém não pediu: é de tremer as peles... Por mim, não encomendei aviso, nem quero ser favoroso... Delrei, del-rei, que eu cá é que não arrecebo dessas conversas, pelo similhante! Destino, quem marca é Deus, seus Apóstolos! E que toque de caixa? É festa? Só se for morte de alguém... Morte à traição, foi que ele Morro disse. Com a caveira, de noite, feito História Sagrada, del-rei, del-rei!... (Ib., p. 22)

Ainda que decida contar o que ouviu, Gorgulho faz questão de tratar em que termos é portador da mensagem. Ele parece conhecer as implicações do trabalho de mensageiro de não humanos e renega qualquer obrigação, dizendo que não pediu para ouvir e que não é dele receber mensagens.

Tanto quanto aqueles personagens que são surdos à língua do morro (o frade, o cientista, o fazendeiro), a galeria de excêntricos ouvintes, aptos a transmitir a fala da serra, diz muito a respeito da natureza dessa comunicação: misantropos, loucos, crianças, o poeta 
violeiro Laudelim, que transforma o recado em cantiga, e por fim o próprio Pê-Boi, que ainda ouve no recado o que ele tem de oracular.

O que nos interessa especificamente nesse conto é a ideia de recado, de fala e de escuta que ele implica. No conto, diferentes estratos de fala, de idioma, de códigos se atravessam, sobrepõem-se. Há os idiomas dos personagens, as línguas que eles falam, que inclui pelo menos dois "estrangeiros". Há os idiomas que correspondem às práticas dos personagens: o cientista, o frade, o fazendeiro, o enxadeiro. Nesse cruzamento de línguas, diversas são as traduções que se sobrepõem.

Mas, além das linguagens humanas, o conto também se dedica a apresentar uma série de outras linguagens, as linguagens dos não humanos. Pássaros, estradas, riachos, morros, urubus se comunicam e fazem redes de relações com pessoas que dificilmente se distinguem da paisagem em que estão arraigadas: enxadeiros, ermitões, poetas.

Há, por fim, um outro tipo de linguagem, a linguagem oracular, que é decifrada pelo personagem justamente na medida em que está numa relação de imanência com a terra e sua polifonia.

A ideia de decifração, da linguagem cifrada da montanha e convertida em oráculo consiste em um tipo de linguagem tão específico quanto a escuta que ela exige, uma escuta que parece estar para além da separação entre palavras e coisas. Os próprios nomes dos personagens, com suas referências astrológicas, testemunham essa imbricação.

Em meio a essa polifonia, e as várias noções de linguagem que ela supõe, é que se pode perguntar: o que poderia ser uma fala da terra no conto de Rosa? O que se poderia entender como escutar o morro? Que tipo de escuta é essa capaz de decifrar um oráculo que é o próprio mundo?

Em 1966, o filósofo Michel Foucault publicará na França As palavras e as coisas. Lê-se na obra as seguintes palavras de Paracelso:

Nós, homens, descobrimos tudo o que está oculto nas montanhas por meio de sinais e correspondências exteriores; e é assim que encontramos todas as propriedades das ervas e tudo o que está nas pedras. Nada há nas profundezas dos mares, nada nas alturas do firmamento que o homem não seja capaz de descobrir. Não há montanha bastante vasta para ocultar ao olhar do homem o que nela existe; isso lhe é revelado por sinais correspondentes. (FOUCAULT, 1981, p. 48-9) 
E o autor conclui: "A adivinhação não é uma forma concorrente do conhecimento; incorpora-se ao próprio conhecimento" (Ib. p. 49). Para Foucault, a episteme clássica, que inaugura o pensamento moderno e tem lugar no século XVII, vai se constituir a partir de uma nova concepção da linguagem, a representação, que intitula um dos capítulos do livro. Essa episteme contrasta com o modo de produzir conhecimento do século XVI, que ele denomina de "a prosa do mundo". É a esse período da prosa do mundo que pertence Paracelso.

Essa episteme do século $X V I$ nos interessa aqui na medida em que uma prosa do mundo pode reverberar uma fala da terra. A descrição de tal episteme, como se vê na citação acima e em contraste com o pensamento moderno que será tema do livro de Foucault, é atravessada pela ideia de um mundo que fala, de uma natureza que se comunica, de um universo cifrado, de tradução e transformação e supõe, antes que uma separação e uma relação de representação, uma continuidade entre linguagem e mundo.

Poucos anos antes, também na França, o antropólogo Lévi-Strauss publicara, como vimos na introdução, uma obra importante para o problema que buscamos tratar aqui. Adiantando-se a Foucault, o antropólogo escreve em O pensamento selvagem:

A verdadeira questão não é saber se o contato de um bico de picanço cura as dores de dente mas se é possivel, de um determinado ponto de vista, fazer 'irem juntos' o bico do picanço e o dente do homem, e, através desses agrupamentos de coisas e de seres, introduzir um princípio de ordem no universo. (1997, p. 24)

Se o interesse de Foucault está numa arqueologia das ciências humanas que supõe uma ruptura com a prosa do mundo por meio da representação, para Lévi-Strauss é de grande interesse para a antropologia de seu tempo pensar de que forma os ameríndios proporcionam ao ocidente outras imagens da relação natureza/cultura, divisão que marca o espírito moderno. De maneiras distintas, a partir de projetos diferentes, ambos circunscrevem o problema da escuta do mundo. A questão que se coloca ao aproxima-los é novamente: qual a natureza dessa escuta?

\section{O chamado da madeira}

Por muito tempo o mito foi pensado como fantasia ou infância do pensamento moderno, segundo uma lógica evolucionista. Trabalhos como $O$ pensamento selvagem e as 
Mitológicas ${ }^{4}$, do antropólogo Claude Lévi-Strauss, propõem, no entanto, uma outra ideia da relação entre (o que ele chama) pensamento selvagem e pensamento domesticado. A relação entre mito e ciência seria de interpenetração e coexistência antes que de sucessão e superação (LÉVI-STRAUSS, 1997, p. 28).

A noção de mito como problematização do que seja uma relação natureza-cultura é fundamental no projeto das Mitológicas. Interessa-me a noção de linguagem que essa outra natureza-cultura supõe quando em contato com o pensamento moderno. Tomo uma conhecida definição de mito do antropólogo:

Didier Eribon: Gostaria de lhe fazer uma pergunta simples: que é um mito?

Claude Lévi-Strauss: Não é uma pergunta simples, é exatamente o contrário, porque se pode respondê-la de vários modos. Se você interrogar um índio americano, seriam muitas as chances de que a resposta fosse esta: uma história do tempo em que os humanos e os animais ainda não eram diferentes. (LÉVISTRAUSS e ERIBON, 2005, p. 195-96)

É digno de nota, ainda mais no contexto deste trabalho, que Viveiros de Castro, ao parafrasear essa definição, transforme a ideia de "diferença" entre humanos e animais em uma diferença no "acesso comunicativo" entre humanos e animais:

Em sua entrevista para Didier Eribon, que Ihe pergunta "O que é um mito?", LéviStrauss responde: "Se perguntarmos isso para um índio americano ele dirá: um mito é uma história do tempo em que os animais falavam". E acrescenta: essa definição, hipotética, mas verossímil, é, na verdade, muito profunda, porque os homens nunca se conformaram por terem obtido a cultura à custa da perda do acesso comunicativo às outras espécies. O mito, então, é uma história do tempo em que os homens se comunicavam com o resto do mundo. (LAGROU e BELAUNDE, 2011, p. 11)

O que nos interessa sobretudo na definição de mito de Lévi-Strauss é, como disse, a definição de linguagem implicada na problematização da relação entre natureza e cultura pensada desde o ponto de vista dos ameríndios. E assim, desde essa outra concepção de linguagem, é que pergunto por uma outra imagem da escuta.

Nossa questão encontra ressonância em uma pergunta que será feita por LéviStrauss a respeito dos mitos de origem da vida breve reunidos na terceira parte de $O$ cru e o cozido, que se divide em A fuga dos cinco sentidos e Cantata do sariguê. Os mitos de origem da vida breve, para o autor, articulam os mitos de origem do fogo aos mitos de origem das

\footnotetext{
${ }^{4}$ As Mitológicas são compostas ao todo por sete livros: a tetralogia original e os três livros subsequentes. A obra tem seu primeiro volume, O cru e o cozido, publicado em 1964 e o último, em 1991, História de Lince.
} 
plantas cultivadas. Os mitos de origem da vida breve são importantes por se distinguirem nos códigos empregados para transmitir uma mesma mensagem. Esses códigos, ainda que diferentes, são códigos de mesmo tipo, trata-se de qualidades sensíveis: "utilizam oposições entre qualidades sensíveis, promovidas, assim, a uma verdadeira existência lógica" (p. 197).

Para tratar da questão da relação entre tais códigos, denominada pelo autor como lógica das qualidades sensíveis, e me referir aos mitos de origem da vida breve, retomo trecho do mito de origem do fogo que serve de referência para os mitos de origem da vida breve, o Mg.

Um rapaz é abandonado pelo cunhado depois de subir para retirar os filhotes de um ninho de araras. Logo o herói é avistado pelo jaguar, que o ajuda a descer e, por não ter filhos, propõe adota-lo. Em sua casa, o jovem conhece o fogo. Depois de sofrer agressões por parte da esposa do jaguar, o herói decide mata-la com as flechas que ganhou de seu pai:

O pai adotivo Ihe dá razão, entrega-Ihe uma provisão de carne assada e explicaIhe como voltar a sua aldeia, descendo por um riacho. Recomenda-lhe que tome cuidado se porventura ouvir chamados durante a caminhada, e responda apenas aos do rochedo e da aroeira, fingindo não ouvir "o doce chamado da árvore podre".

O herói se põe a caminho, atende aos primeiros chamados e - esquecendo as recomendações do jaguar - responde também ao terceiro. Por isso a vida dos homens é abreviada. Se o rapaz tivesse respondido apenas aos dois primeiros chamados, os homens viveriam tanto quanto o rochedo e a aroeira. (2004, p. 94)

Em seu estudo da série de mitos reunidos como aqueles que tratam da origem da vida breve, o autor se coloca então à questão que nos interessa aqui:

Contudo, o mito apinayé levanta um problema que ainda não resolvemos. Que sentido devemos dar à estranha noção de um chamado, proveniente de um ser, vegetal ou mineral, desprovido de capacidade de articulação? (Ib., p. 183)

Se de um lado Lévi-Strauss trata do sentido da audição, ele também se refere ao código verbal ao falar em "capacidade de articulação". O autor, porém, se pergunta, reabrindo a questão: que sentido dar a um chamado como esse?

Ao estabelecer uma relação dos três elementos (rocha, madeira dura, madeira podre) com os cinco sentidos como chave de leitura dessa série de mitos, o antropólogo conclui:

Assim, compreende-se o sentido muito preciso que convém dar ao vocalismo da pedra e da madeira: os emissores de ruído devem ser escolhidos de tal modo que possuam igualmente outras conotações sensoriais. São operadores que permitem exprimir o isomorfismo de todos os sistemas de oposições relativos aos 
sentidos, e, portanto, colocar como um todo um grupo de equivalências que associa a vida e a morte, a alimentação vegetal e o canibalismo, a podridão e a imputrescibilidade, a moleza e a dureza, o silêncio e o ruído. (Ib., p. 184)

Desse modo, à rocha estariam associados: o chamado ruidoso (auditivo), as plantas cultivadas (gustativo), o imputrescível (olfativo), o duro (tátil). Em oposição, à madeira podre seguiriam: o chamado "doce" (auditivo), a carne humana (gustativo), o pútrido (olfativo), o mole (tátil).

Essa lógica das qualidades sensíveis colocou a partir de Lévi-Strauss um problema de enorme importância para a etnologia ameríndia e amazônica: trata-se da tradução intersemiótica em uma ontologia da diferença, um mundo cuja referência é antes a diferença e a transformação do que a identidade e o acabamento.

Um dos exemplos é o dos estudos da arte sonora ameríndia 5 . A partir das Mitológicas e da lógica das qualidades sensíveis que elas problematizam, tornaram-se evidentes aos etnomusicólogos as muitas implicações do ato de isolar a música ou o som para estuda-lo como expressão independente. Isso caso se trate de levar em conta as descrições dos nativos. E supondo-se que o ritual seja abordado conforme Lévi-Strauss propõe abordar o mito, isto é, tomando-o como escrita em vez de como objeto de escrita. Desse modo, no ritual, compreende-se que um som pode ser "traduzido" em uma imagem, assim como uma dança ou uma pintura corporal pode transformar um corpo. Ou ainda, tal como no mito, a resposta à doçura (paladar) de um chamado (audição) pode mudar a consistência (tato) do corpo, transformando sua duração. Conforme Lévi-Strauss, pensadas como códigos, as qualidades sensíveis nessa ontologia não são imaginadas nem produzem conhecimento separadamente, antes operam por transformações.

\section{Nova aliança}

Retomo agora o comentário de Viveiros de Castro à definição de mito de LéviStrauss, quando diz que os humanos nunca se conformaram com a perda do acesso comunicativo às outras espécies:

\footnotetext{
${ }^{5}$ Tratei desse problema em outra ocasião (MATTOS, 2017b) e remeto aos estudos fundamentais da etnomusicologia que primeiro souberam explorar nesse sentido as possibilidades abertas pelas Mitológicas, em trabalhos como os de Seeger (2015) e Menezes Bastos (2007) e ainda Viveiros de Castro (2002), Lagrou (2007), Barcelos Neto (2012) e, mais recentemente, Severi (2014).
} 
Isso se liga à cosmologia pessimista do próprio Lévi-Strauss. Em um artigo em homenagem a Rousseau ele observa amargamente que os seres humanos, ao se separarem dos outros animais, abriram o caminho para as separações internas ao gênero humano - o etnocentrismo, o racismo -, e que esse narcisismo é o caminho para nossa perdição cósmica. Essa visão pessimista e apocalíptica de Lévi-Strauss foi se acentuando com o tempo, mas já está presente desde Tristes trópicos, um livro que, do título à última página, é marcado por um tom austero e sombrio. (Ib., p. 11)

Da cosmologia ameríndia à cosmologia do próprio autor, ironiza o comentador. Esse pessimismo quanto à conquista da cultura (de que a vida breve é uma das consequências) a que se refere Viveiros de Castro é também o pessimismo de Lévi-Strauss em relação às "sociedades quentes". Essa dobra vai conduzir o antropólogo a uma das primeiras elaborações das implicações físicas (ambientais) e metafísicas (evolucionismo, colonialismo, racismo) do projeto moderno. Essa questão incide diretamente no tema aqui proposto, na medida em que Lévi-Strauss faz ecoar em sua obra aquilo que o pensamento ameríndio trata nos termos de uma escuta da terra.

As duas guerras que marcaram o ocidente no século $X X$ afetaram decisivamente o otimismo civilizatório do colonialismo moderno. Valéry (1957) sintetiza já em 1919 essa mudança: "Nós civilizações agora sabemos que somos mortais" ${ }^{6}$. Interessa a noção de limite que ele aponta. É nesse contexto que o pessimismo de Lévi-Strauss pode ser pensado como marca de sua "cosmologia".

É também nesse sentido que a entropia ocupará o pensamento do antropólogo, ao ponto de ele criar o neologismo entropologia (LÉVI-STRAUSS, 2010). Isso demonstra que, em vez de alheia aos debates sobre as transformações do pensamento científico, sua obra não pode ser compreendida senão como parte desses debates.

As noções de ordem e organização tanto quanto as de reversibilidade e continuidade, portanto, não são trabalhadas de forma ingênua pelo autor, mas visando debates em curso nas ciências que remontam ao século XIX, como nesse caso da termodinâmica.

Essa mesma mistura, que se apresenta em Lévi-Strauss, de desencanto com tais sociedades quentes que convertem biodiversidade em energia, combinado a um fascínio pelas práticas científicas parece reverberar também em $A$ nova aliança, obra de Prigogine e

\footnotetext{
${ }^{6}$ No original, em inglês: "We later civilizations ... we too know that we are mortal" (Crisis of the mind, 1919). Disponível em: http://www.historyguide.org/europe/valery.html Acesso em outubro de 2019.
} 
Stengers. A obra propõe repensar a tradição da ciência moderna desde as transformações que marcam o pensamento científico do século $X X$, notadamente a termodinâmica, problematizando a imagem da relação com o mundo que ela propõe, marcada pelas ideias de neutralidade e exploração:

Como Jacques Monod nos anunciava, chegou o tempo de assumir os riscos da aventura dos homens; mas, se podemos fazê-lo, é porque, doravante, é esse o modo da nossa participação no devir cultural e natural, é essa a lição que a natureza enuncia quando a escutamos. O saber científico, extraído dos sonhos de uma revelação inspirada, quer dizer, sobrenatural, pode descobrir-se hoje simultaneamente como "escuta poética" da natureza e processo natural nela, processo aberto de produção e invenção, num mundo aberto, produtivo e inventivo. Chegou o tempo de novas alianças, desde sempre firmadas, durante muito tempo ignoradas, entre a história dos homens, de suas sociedades, de seus saberes, e a aventura exploradora da natureza. (1991, p. 226)

São essas palavras que finalizam a obra de 1979. Se o paradigma newtoniano supunha a reversibilidade, o equilíbrio e a ordem, a ciência que vinha se constituindo desde o século XIX, tendo a termodinâmica e a entropia em seu centro, baseava-se em outra imagem da relação entre humano e seu mundo, marcada pela incerteza, pela irreversibilidade e pelo caos.

Para os autores, a ciência de nossa época deverá supor uma outra relação com o mundo, mediada por uma escuta poética. Porém, a que se referem os autores com a expressão "escuta poética"? A expressão parece conter todo o projeto do livro, livro que, por seu caráter de manifesto, parece conter todo o projeto dos autores. Para responder a ela, voltome ao esclarecimento que eles fazem da expressão:

Assim a ciência se afirma hoje como ciência humana, ciência feita por homens e para homens. No seio de uma população rica e diversa em práticas cognitivas, nossa ciência ocupa a posição singular de escuta poética da natureza - no sentido etimológico em que o poeta é um fabricante - exploração ativa, manipuladora e calculadora, mas doravante capaz de respeitar a natureza que ela faz falar. É provável que esta singularidade continue a excitar a hostilidade daqueles para os quais todo cálculo e toda manipulação são suspeitos, mas não deviam muito legitimamente suscitar certos juízos sumários da ciência clássica. (lb., p. 215)

E em sua obra A invenção das ciências modernas, Stengers faz a seguinte observação:

Observemos a esse respeito que La nouvelle alliance, publicada bem antes que se falasse de "nova ciência", não defendia tal perspectiva. A expressão "escuta poética da natureza" escandalizou aqueles que "esqueceram" de ler o que se 
seguia: "no sentido etimológico em que o poeta é um fabricante". E que de novo confundiram a ideia da "capacidade", para a física, de "respeitar a natureza que ela faz falar" com a ideia de respeito à natureza tal como ela se apresenta. (2002, p. 175)

Em lugar do triunfalismo da verdade universal como resultado de um inquérito autoritário, que imagina o humano fora da natureza, a imagem do conhecimento desde a termodinâmica e a entropia supõe o desequilíbrio e a incerteza, colocando o problema da energia no centro do debate. A política que a ciência moderna supunha excluir da sua prática, retornaria violentamente com o aquecimento global e o Antropoceno.

Segundo Prigogine e Stengers, a nova aliança supõe uma nova escuta, outro tipo de abordagem do mundo que aquele que marca o espírito de exploração ilimitada do capitalismo moderno. Ao mesmo tempo em que esse outro modo de pensar supõe uma outra escuta do mundo, ele supõe também uma maneira diferente de se relacionar com os outros saberes:

Devemos aprender, não mais julgar a população dos saberes, das práticas, das culturas produzidas pelas sociedades humanas, mas a cruzá-los, a estabelecer entre eles comunicações inéditas que nos coloquem em condições de fazer face às exigências sem precedentes da nossa época. (1991, p. 225)

Esses mesmos povos não modernos são aqueles a partir dos quais Lévi-Strauss já nos anos 1960 deduziu a noção de pensamento selvagem, também ele um pensamento poético, também ele resultado de uma problematização da ideia de relação.

\section{A terra fala?}

Exposição "A fala da terra": Nós acadêmicos do Curso de Licenciatura Indígena, UFAC, estamos aqui para apresentar nossa pesquisa que tem como o tema a Fala da Terra.

Nós acadêmicos tivemos como experiência de realizar um projeto, através de cantos de animais, pássaros, gritos, o silêncio da natureza, ventos, de como percebemos o que a terra está pedindo, como ela pede socorro. Percebemos através disso, de uma pesquisa feita na Universidade. E foi aí que nós acadêmicos resolvemos nos aprofundar mais.

A pesquisa foi feita na comunidade, onde realizamos essa pesquisa do conhecimento do nosso povo, esse registro das histórias que temos na nossa biblioteca indígena. Só assim que nós estamos conseguindo realizar o nosso conhecimento, do nosso interesse que queremos apresentar e deixar registrado para que os alunos e a comunidade, as futuras gerações conheçam nossas histórias. (LICENCIATURA INDÍGENA, 2017) 
Como se percebe a partir do pensamento moderno, o campo de forças em que nos inserimos determina as regras do jogo. Ao se abrir para os povos ameríndios, a universidade o faz inserindo esses acadêmicos em um jogo de cartas marcadas, em um campo de ideias pré-definido. Essa relação que visa colonizar humanos e não humanos está na própria noção de pessoa e na sensibilidade que ela supõe, traduzida no modo de imaginar o ato e o sujeito de conhecimento ocidentais.

A fala da terra consistiria assim em um procedimento que se assemelha àquele adotado pelo pintor Francis Bacon e descrito por Deleuze (2007, p. 96) nos termos de uma concepção de linguagem outra. Trata-se de propor uma intervenção em um campo de forças dominado pelo clichê. No caso de Bacon, de lançar a esmo uma quantidade de tinta na tela em branco e passar a compor a partir dessa intervenção, pois, segundo ele, a tela branca nunca está de fato branca, ela está coberta de clichês. A fala da terra enquanto procedimento visa desestabilizar a concepção de linguagem que a universidade supõe como consensual. Essa desestabilização se deve à inserção, no campo de forças, de outros agentes (a terra e todos aqueles que ela faz falar) e da concepção de linguagem que sua presença implica.

O objetivo é afetar esse campo de forças que já foi ordenado em torno, por exemplo, do contato com os missionários e seu livro, com o Estado e sua burocracia, com os antropólogos e as ideias de cultura e de história, com a escola e o letramento, por fim, com a própria universidade e seu espírito científico modernizador. A fala da terra visa desestabilizar esse campo de forças em favor do pensamento mítico, suas práticas e as noções de pessoa e linguagem que o atravessam. Como efeito desse reordenamento do campo de forças, a reação da turma foi de desnorteamento.

Era o primeiro dia de aula de Tópicos em pesquisa, disciplina da área de Linguagens e Artes. Propus meu objetivo de repensar com eles as ideias de linguagens e de pesquisa que orientavam a área. Frente à pergunta inesperada houve inicialmente uma reação de ceticismo. Supõe-se que a universidade não seja um lugar em que a terra deva falar. Após esses primeiros momentos de desnorteamento, uma primeira resposta: - Imagina professor, a terra falar, e a terra tem boca pra falar? Depois dessa primeira resposta, os estudantes passaram a falar entre si, inclusive em seus idiomas, até que, em meio a essa conversação, 
alguém pediu a palavra e disse: - Pois eu penso que a terra fala sim, a terra fala através das nossas músicas, através de um pássaro que dá um aviso, de um inseto que adivinha a chuva.

Nesse momento, o grupo já tinha percebido as muitas possibilidades abertas pela questão e tinha início sua apropriação do termo. Cada um queria falar de que maneira entendia, desde seu conhecimento, que a terra falava. Suas propostas consideravam o conhecimento que eles compartilhavam com suas comunidades e possibilitavam pensar desde esse conhecimento os saberes da universidade, incluindo a ideia de linguagem dada por certa na academia.

Percebo que a fala da terra possibilitou a esses pesquisadores modular uma voz acadêmica, operar com seus conhecimentos frente ao saber da universidade. Ela permitiu um recurso ou procedimento de simetria ou de reversibilidade que lhes possibilitou lidar a seu modo com aquilo que opera na academia como regra, como senso comum, como convenção.

A fala da terra supõe uma concepção de linguagem atravessada por uma outra ideia do que seja comunicação. Referindo-se à concepção de linguagem que baseia o pensamento ocidental, Deleuze e Guattari escrevem: "Não nos falta comunicação, ao contrário, nós temos comunicação demais, falta-nos criação" (2010, p. 131). A oposição entre comunicação e criação (nas práticas da filosofia e da arte) interessa muito aqui, pois a fala da terra opera antes na chave desse conceito de criação do que na chave da ideia de comunicação que, segundo os autores, define as práticas de conhecimento do ocidente moderno.

\section{A escuta dos outros}

O tema a respeito da fala da terra, qual sua expressão, o que ela escreve para visão dos huni kui e como se ouvir a maneira que a terra fala para ilustrar nossa visão a partir da prática cultural.

Após ouvir a fala dos demais participantes da reunião do tema abordado, chegamos ao seguinte consenso e encaminhamento:

- A terra fala através das florestas, rios, pássaros, aldeias, pajé e outros.

Foram também falados como: qual a fala da terra com os nawa? As ideias expressadas pelos huni kui:

- Os nawa são muito capitalista vendo que a sociedade é movida pelo dinheiro, a tecnologia avançada que polui nossas riquezas naturais e o futebol que os nawa cultua com Deus de ouro, exemplo: copa do mundo. (ALDECINO YUBE, Diário de pesquisa) 
O interesse das comunidades pelo tema nos conduziu por uma cartografia que revelou ainda uma outra pergunta: - Com quem e como se aprende a fala da terra? Por meio dessa pergunta que se definiram campos bastante diversos como: rituais, plantio, cantos, mitos, caça, parto, xamanismo e ayahuasca, entre outros. Segundo eles, a fala da terra é aprendida com os animais, tanto quanto com os mais velhos.

Em seus territórios, os acadêmicos iniciaram suas pesquisas perguntando ao povo: a terra fala? A questão intrigou e provocou reações diversas. A partir da interação e do interesse da comunidade no tema, diversos especialistas passaram a relatar como entendiam desde seus saberes que a terra poderia falar.

Também em atividade com os povos é que se instituiu uma terceira pergunta a respeito da fala da terra. Tal questão apresenta outras tantas implicações para o entendimento de uma noção de escuta que atravessa esse debate em torno de uma concepção de linguagem diferenciada. A questão é a seguinte: - Os brancos ouvem a fala da terra? Nesse eixo foram debatidas questões como tecnologia, capitalismo e ciência. Foi também em torno das questões mobilizadas por essa pergunta que realizamos um debate dos acadêmicos indígenas com estudantes do curso de Engenharia florestal, organizado junto com a professora Francesca Salla.

Os estudantes da florestal receberam os indígenas em sua sala no mais afável espírito de tolerância, como verdadeiros anfitriões recebendo aqueles que supunham os visitantes. Ensinados a pensar a floresta como engenheiros, isto é, em termos de inventário, recursos, exploração, manejo, administração da floresta, árvores comerciais, indivíduos arbóreos, ciclos de corte, espécies comerciais entre outros, esses estudantes ficaram mudos quando questionados pelos indígenas a respeito da fala da terra.

Os brancos ouvem a fala da terra? Para problematizar a questão recorro aos conceitos de escuta e surdez em torno dos quais orbita boa parte da narrativa de Kopenawa em A queda do céu (2015):

Os brancos não pensam nessas coisas. Se o fizessem não arrancariam da terra tudo o que podem, sem se preocupar. É para acabar com isso que quero fazer com que eles ouçam as palavras que os xapiri me deram no tempo do sonho. (Ib., p. 361)

Assim, meu sogro costuma me dizer: "Você deve contar isso aos brancos! Eles têm de saber que por causa da fumaça maléfica dessas coisas que eles tiram da terra estamos morrendo todos, um atrás do outro!". É o que agora estou tentando explicar aos brancos que se dispuserem a me escutar. (Ib., p. 371) 
Conforme explica Kopenawa, o ouvir yanomami tem sua especificidade (ALBERT, 2016). Segundo ele, foi Titiri, o espírito da noite, que no primeiro tempo ensinou o wayamuu e o yaimuu, suas falas cerimoniais, dizendo: "Que essa fala da noite fique no fundo de seu pensamento! Graças a ela, vocês serão realmente ouvidos por aqueles que vierem visita-los" (Ib., p. 378):

Quando dizemos as coisas só com a boca, durante o dia, não nos entendemos de fato. Escutamos o som das palavras que nos são dirigidas, mas as esquecemos com facilidade. Durante a noite, ao contrário, as palavras ditas em wayamuu ou em yaimuu vão se acumulando e penetram no fundo de nosso pensamento. Revelam-se com toda a clareza e podem ser efetivamente ouvidas. (Ib., p. 378)

Contudo, num outro sentido, quando Kopenawa fala da incapacidade dos brancos em "ouvir", sua inépcia para o "sonhar" e para o "ver", percebe-se que esses sentidos se tornam indiscerníveis. Além da "fumaça maléfica das coisas que tiram da terra", ele atribui à escrita alfabética a incapacidade dos brancos em ver-ouvir-sonhar.

Como também destacou Peter Gow (2014) em um comentário a A queda do céu, a ideia de um apelo à escuta é central no projeto. Essa ideia se confirma pela história que entendo dar origem ao livro. Trata-se do episódio narrado por Albert em seu pós-escrito. Ele conta que Kopenawa, ao tomar conhecimento da destruição em curso em um importante local do território yanomami, declarou em português: "Os brancos não sabem sonhar, é por isso que destroem a floresta desse jeito" (Ib., p. 531).

Assim como os conhecimentos yanomami se ordenam em torno de uma aprendizagem sensorial que pode ser pensada como uma arte do ouvir (Albert, 2016), Kopenawa se propõe a compreender o que pode fazer com que os brancos tenham se tornado um povo incapaz de ouvir, ao mesmo tempo em que tenha assumido para si a paradoxal tarefa de anunciar a queda do céu para os inimigos que não sabem sonhar.

\section{Conclusão}

A partir da noção de fala da terra, desenvolvida em um conjunto de pesquisas de acadêmicos indígenas da LI da UFAC - Floresta junto a suas comunidades com o intuito de formular uma noção de linguagem apropriada às pesquisas acadêmicas indígenas, busquei 
pautar a importância de certa inflexão nas noções de fala e de escuta em alguns autores que se debruçaram sobre os limites do pensamento moderno ocidental.

O pensamento mítico e a concepção de linguagem que tal pensamento aponta, devidamente estudados na etnologia de Lévi-Strauss, tem um importante papel nos debates contemporâneos a respeito das alternativas ao pensamento moderno e à relação predatória com o planeta que ele supõe.

Os mitos ameríndios exploram variamente a comunicação entre humanos e não humanos. As origens dos mais importantes conhecimentos se encontram nas diversas formas da relação desses grupos com os não humanos. Inclusive, grande parte dos rituais que ordenam sua vida social e suas práticas se dedica a atualizar essas relações.

Assim, a ideia de um mundo que se constitui de relações com não humanos não é estranha aos acadêmicos indígenas. Caça, plantio, xamanismo, parto, comensalidade, precauções e resguardos: práticas de conhecimento marcadas por uma socialidade e uma política com os não humanos das quais os mitos resultam.

O objetivo específico de retomar aqui o trabalho realizado em $2017 \mathrm{com}$ esses pesquisadores indígenas, assim como referir às palavras de Kopenawa, foi ainda abordar a noção de escuta inerente ao conceito de fala da terra e às práticas de conhecimento ameríndias. Essa noção de escuta quando se volta para nós, (como se voltou para os estudantes de engenharia florestal) permite que problematizemos os termos em que se dá a relação do conhecimento moderno e suas práticas com os outros seres do planeta.

Em um século em que as tecnologias desenvolvidas em laboratório possibilitam a exploração desenfreada do planeta e o extermínio de humanos e outras espécies em favor do capital (tanto quanto sua previsão, informação e responsabilização), os pesquisadores indígenas (e seus saberes) se encontram na universidade e perguntam: - os brancos ouvem a fala da terra?

\section{Bibliografia Citada}

ALBERT, Bruce. "La forêt polyglotte." In: Le Grand Orchestre des Animaux (Catálogo da exposição). Paris : Fondation Cartier pour l'art contemporain, 2016.

BARCELOS NETO, Aristóteles. "A serpente de corpo repleto de canções: um tema amazônico sobre a arte do trançado." Revista de Antropologia, v. 54, n. 2, 2012. 
CALLICOTT, Christina. Comunicação entre espécies na Amazónia ocidental: a música como forma de conversação entre plantas e pessoas. Tradução Catarina Barros. Ed. Chão da feira, 2017.

CANDIDO, Antonio. Textos de intervenção. Organização Vinicius Dantas. São Paulo: Editora 34/Duas Cidades, 2002.

COLLET, Celia Leticia Gouvea (Org.). Atualizar o mito: Práticas indígenas na universidade. Rio Branco: Nepan Editora, 2018.

DELEUZE, G.; GUATTARI, F. O que é a filosofia? Tradução Bento Prado Jr. e Alberto Alonso Muñoz. São Paulo: Ed. 34, 2010.

DELEUZE, G.; PARNET, C. Diálogos. Tradução Eloisa Araújo Ribeiro. São Paulo: Editora Escuta, 1998.

DELEUZE, G. Francis Bacon: lógica da sensação. Tradução Roberto Machado et al. Rio de Janeiro: Jorge Zahar, 2007.

FOUCAULT. M. As palavras e as coisas. Uma arqueologia das ciências humanas. Tradução Salma Tanus Muchail. São Paulo, Martins Fontes, 1981.

GOW, Peter. "'Listen to me, listen to me, listen to me, listen to me... 'A brief commentary on The falling sky by Davi Kopenawa and Bruce Albert." Hau: Journal of Ethnographic Theory 4 (2): 301-309, 2014.

KAXINAWA, Norberto Sales. Nixpu Pima - O Ritual de Passagem do Povo Huni Kuin. Trabalho de Conclusão de Curso, Licenciatura Indígena, UFAC - Floresta, 2013.

KOPENAWA, Davi; ALBERT, Bruce. A queda do céu. Palavras de um xamã yanomami. Tradução Beatriz Perrone-Moisés. São Paulo: Companhia das Letras, 2015.

LAGROU, Els. A fluidez da forma: arte, alteridade e agência em uma sociedade amazônica (Kaxinawa, Acre). Rio de Janeiro: Topbooks, 2007.

LAGROU, Elsje; BELAUNDE, Luisa Elvira. "Do mito grego ao mito ameríndio: Uma entrevista sobre Lévi-Strauss com Eduardo Viveiros de Castro." Sociol. Antropol. [online]. Vol.1, n.2, pp.9-33, 2011.

LATOUR, Bruno. Jamais fomos modernos. Tradução Carlos Irineu da Costa. Rio de Janeiro: Ed. 34, 1994 .

Enquête sur les Modes d'Existence: une Anthropologie des Modernes. Paris:

Éditions La Découverte, 2012.

LÉVI-STRAUSS, Claude. O pensamento selvagem. Tradução de Tânia Pellegrini. Campinas: Papirus, 1997. 
Tristes trópicos. Tradução Rosa Freire D’Aguiar. São Paulo: Companhia das Letras, 2010.

"A estrutura dos mitos." In: Antropologia Estrutural. Rio de Janeiro: Tempo Brasileiro, 1975.

O cru e o cozido - Mitológicas I. Tradução Beatriz Perrone-Moisés. São Paulo:

Cosac \& Naify, 2004.

LÉVI-STRAUSS, Claude; ERIBON, Didier. De perto e de longe. Tradução Julieta Leite e Léa Mello. São Paulo: Cosac \& Naify, 2005.

LICENCIATURA INDÍGENA, UFAC - Floresta. Catálogo da exposição A fala da terra. Cruzeiro do Sul: LABI - Laboratório de Imagem e Som, UFAC - Floresta, 2017.

MATTOS, Amilton Pelegrino de. O que se ouve entre a opy e a escola? Corpos e vozes da ritualidade guarani. Dissertação de mestrado. Faculdade de Educação da Universidade de São Paulo, 2005.

"Atualizar o mito." In: COLLET, Celia Leticia Gouvea (Org.). Atualizar o mito: Práticas indígenas na universidade. Rio Branco: Nepan Editora, 2018a.

. "Entre imagens, corpos e terra: transformações do MAHKU - Movimento dos Artistas Huni Kuin". ClimaCom [Online], Campinas, 4(10), 2017. Disponível em: http://climacom.mudancasclimaticas.net.br/? $p=7673$

. "Máquinas de visão: O MAHKU - Movimento dos Artistas Huni Kuin em suas práticas de experimentação visual". Metamorfose: arte, ciência e tecnologia, 3(1), Salvador, 2018b. Disponível em:

https://portalseer.ufba.br/index.php/metamorfose/article/view/24509/16946

MATTOS, Amilton; IBÃ, Huni Kuin. "Por que canta o MAHKU - Movimento dos Artistas Huni Kuin?" Revista GIS - Gesto, Imagem e Som, USP. 2(1): 61-82, São Paulo, 2017.

MENESES BASTOS, Rafael José de. Música nas sociedades indígenas das terras baixas da América do Sul: Estado da arte. Mana, Rio de Janeiro, v. 13, n. 2, p. 293-316, 2007.

PINHANTA, Valdete da Silva. Registro Artístico de Musicalidades do Ritual Piyaretsi do povo Ashenika do rio Amônia. Trabalho de conclusão de Curso em Licenciatura Indígena, UFAC Floresta, 2013.

PRIGOGINE, Ilya; STENGERS, Isabelle. A nova aliança: metamorfose da ciência. Tradução Miguel Faria e Maria Joaquina Trincheira. Brasília: Editora UnB, 1991.

PUYANAWA, Vari Sharanaya. Nupanare - Músicas usadas na transmissão de conhecimento Puyanawa. Trabalho de conclusão de Curso em Licenciatura Indígena, UFAC - Floresta, 2013. 
ROSA, João Guimarães. "O recado do morro." In: No Urubuquaquá, no Pinhém. Rio de Janeiro: J. Olympio, 1978.

SEEGER. Anthony. Por que cantam os Kisêdjê - uma antropologia musical de um povo amazônico. Tradução Guilherme Werlang. São Paulo: Cosac e Naify, 2015.

SEVERI, Carlo. "Transmutating beings: A proposal for an anthropology of thought". HAU: Journal of Ethnographic Theory, v. 4, n. 2, p. 41-71, 2014.

SIÃ, Tadeu Mateus Kaxinawa. Cantos de Yube Kene: A malha da Jiboia no desenho e na música huni kuin. Trabalho de conclusão de Curso em Licenciatura Indígena, UFAC Floresta, 2013.

STENGERS, Isabelle. A invenção das ciências modernas. Tradução Max Altman. São Paulo: Ed. 34, 2002.

UFAC - FLORESTA. Projeto Pedagógico Curricular do Curso de Licenciatura Indígena. UFAC: Cruzeiro do Sul, 2015.

VALENTIM, Marco Antonio. Extramundanidade e sobrenatureza: ensaios de ontologia infundamental. Florianópololis: Cultura e Brabárie, 2018.

VALÉRY, Paul." La Crise de I’Esprit." In: Variété. OEuvres I. Paris: Gallimard, Pléiade, 1957.

VIVEIROS DE CASTRO, Eduardo. A inconstância da alma selvagem, São Paulo: Cosac \& Naify, 2002.

. "Perspectival Anthropology and the Method of Controlled Equivocation".

Tipití, vol. 2, n. 1: 3-22, 2004.

. Metafísicas canibais: Elementos para uma antropologia pós-estrutural. São

Paulo: Cosac \& Naify, 2015.

Ciclo UFMG, 9o: Desafios Contemporâneos - Eduardo Viveiros de Castro, 2018.

Disponivel em https://youtube.com/watch?v=_PfE54pj1wU\&t=30475 Consultado em outubro de 2019.

WAGNER, Roy. A invenção da cultura. São Paulo: Cosac Naify, 2010.

\footnotetext{
'Professor da Licenciatura indígena da Universidade Federal do Acre. Doutorando pelo PPGSA do Instituto de Filosofia e Ciências Sociais da UFRJ.

E-mail: amilton.mattos@yahoo.com.br
} 